\title{
Using a mobile health app to improve patients' adherence to hypertension treatment: A non-randomized clinical trial
} \author{
Sant'Anna Alves ${ }^{1}$, Ana Carolina Bertoletti De Marchi ${ }^{1,2}$ \\ ${ }^{1}$ School of Physical Education and Physiotherapy, University of Passo Fundo, Passo Fundo, RS, Brazil \\ 2 Institute of Exact Sciences and Geosciences, University of Passo Fundo, Passo Fundo, RS, Brazil \\ 3 Faculty of Applied Health Sciences, Brock University, St. Catharines, ON, Canada \\ Corresponding Author: Ericles Andrei Bellei \\ Email address: 168729@upf.br
}

Simiane Salete Volpi ${ }^{1}$, Daiana Biduski ${ }^{2}$, Ericles Andrei Bellei ${ }^{\text {Corresp., }}{ }^{2}$, Danieli Tefili ${ }^{1}$, Lynn McCleary ${ }^{3}$, Ana Luisa

Poor adherence to hypertension treatment increases complications of the disease and is characterized by a lack of awareness and acceptance of ongoing treatment. Mobile health (mHealth) apps can optimize processes and facilitate access to health information by combining treatment methods with attractive solutions. In this study, we aimed at verifying the influence of using an mHealth app on patients' adherence to hypertension treatment, also examining how user experience toward the app influenced the outcomes. A total of 49 participants completed the study, men and women, diagnosed with hypertension and ongoing medical treatment. For 12 weeks, the control group continued with conventional monitoring, while the experimental group used an mHealth app. From the experimental group, at baseline, $8 \%$ were non-adherent, $64 \%$ were partial adherents and $28 \%$ were adherent to the treatment. Baseline in the control group indicated $4.2 \%$ non-adherents, 58.3\% partial adherents, and 37.5\% adherents. After follow-up, the experimental group had an increase to $92 \%$ adherent, $8 \%$ partially adherent, and $0 \%$ nonadherent $(P<0.001)$. In the control group, adherence after follow-up remained virtually the same $(P \geq 0.999)$. Results of user experience were substantially positive and indicate that the participants in the experimental group had a satisfactory perception of the app. In conclusion, this study suggests that using an mHealth app can empower patients to manage their own health and increase adherence to hypertension treatment, especially when the app provides a positive user experience. 


\title{
Using a mobile health app to improve patients' adherence to hypertension treatment: A non-randomized clinical trial
}

${ }_{4}$ Simiane Salete Volpi ${ }^{1}$, Daiana Biduski ${ }^{2}$, Ericles Andrei Bellei ${ }^{2}$, Danieli Tefili ${ }^{1}$, Lynn McCleary ${ }^{3}$, Ana Luisa Sant'Anna Alves ${ }^{1}$, and Ana Carolina Bertoletti De Marchi ${ }^{1,2}$

\author{
${ }^{1}$ School of Physical Education and Physiotherapy, University of Passo Fundo, Passo \\ Fundo, RS, Brazil \\ ${ }^{2}$ Institute of Exact Sciences and Geosciences, University of Passo Fundo, Passo \\ Fundo, RS, Brazil \\ ${ }^{3}$ Faculty of Applied Health Sciences, Brock University, St. Catharines, ON, Canada
}

Corresponding author:

Ericles Andrei Bellei ${ }^{1}$

Email address: 168729@upf.br

\begin{abstract}
Poor adherence to hypertension treatment increases complications of the disease and is characterized by a lack of awareness and acceptance of ongoing treatment. Mobile health (mHealth) apps can optimize processes and facilitate access to health information by combining treatment methods with attractive solutions. In this study, we aimed at verifying the influence of using an mHealth app on patients' adherence to hypertension treatment, also examining how user experience toward the app influenced the outcomes. A total of 49 participants completed the study, men and women, diagnosed with hypertension and ongoing medical treatment. For 12 weeks, the control group continued with conventional monitoring, while the experimental group used an mHealth app. From the experimental group, at baseline, $8 \%$ were non-adherent, $64 \%$ were partial adherents and $28 \%$ were adherent to the treatment. The baseline in the control group indicated $4.2 \%$ non-adherents, $58.3 \%$ partial adherents, and $37.5 \%$ adherents. After follow-up, the experimental group had an increase to $92 \%$ adherent, $8 \%$ partially adherent, and $0 \%$ non-adherent $(P<0.001)$. In the control group, adherence after follow-up remained virtually the same $(P \geq 0.999)$. Results of user experience were substantially positive and indicated that the participants in the experimental group had a satisfactory perception of the app. In conclusion, this study suggests that using an mHealth app can empower patients to manage their health and increase adherence to hypertension treatment, especially when the app provides a positive user experience.
\end{abstract}

\section{INTRODUCTION}

High blood pressure (>140/90 mmHg), also known as hypertension (Egan and Zhao, 2012), is a concerning public health issue - one-third of patients with hypertension have not been diagnosed and among those who are diagnosed, about half do not follow treatment properly (Kitt et al., 2019). When patients follow the recommendations provided by health professionals, both pharmacological and non-pharmacological, there is an improvement in treatment adherence (Chudiak et al., 2017; Uchmanowicz et al., 2018; Da Silva et al., 2017). Adherence is the extent to which a person's behavior-taking medication, following a diet, and/or executing lifestyle changes corresponds with agreed recommendations from a health-care provider (Sabaté, 2003). Poor adherence to hypertension treatment is a complex issue affected by multiple factors, including patients' age, educational level, number of prescribed medications, social-economic status, number of comorbidities, lack of awareness, and others (Mancia et al., 2013; Miller, 2016; Uchmanowicz et al., 2018; $\mathrm{Ni}$ et al., 2019). Therefore, the treatment requires permanent motivation to maintain daily health care (Chudiak et al., 2017).

Non-pharmacological approaches for hypertension include diet modifications, self-monitoring of blood 
pressure, and other health behaviors and habits (Gewehr et al., 2018), which could all be strengthened with the support of technology. Mobile health apps (mHealth) offer a way to monitor patient's health conditions, such as diet, body weight, blood pressure, mood, and sleep, among others, and can be used in combination with traditional health care to facilitate access to health information (Hui et al., 2019; Ni et al., 2018; Alessa et al., 2019; Galligioni et al., 2015; Albrecht et al., 2017). Thus, mHealth apps might increase awareness of needed behavioral changes and the adherence to healthy habits, along with the health care provider's awareness of what the patient is doing (Paglialonga et al., 2018; Bellei et al., 2020). Moreover, mHealth apps can guide illness self-management, providing patients with psychological support and decision-making support, and facilitating collaboration between health professionals, patients, and their families (Lu et al., 2019).

To improve adherence, patients need frequent encouragement, guidance and reminders about lifestylerelated to hypertension management, monitoring blood pressure symptoms, and health status indicators (Whelton, 2015; Da Silva et al., 2017). Mobile health apps can remind patients of healthy habits, such as checking blood pressures regularly and taking medications as prescribed, all leading to better treatment adherence (Kitt et al., 2019; Xiong et al., 2018). However, the use of mHealth interventions also requires long-term studies to understand the real impact of technology in health, and to investigate human factors associated with perceptions and usage (Dick et al., 2016; McLean et al., 2016; Toro-Ramos et al., 2017; Biduski et al., 2020).

Regarding human factors, the concept of user experience includes all aspects of interaction and involves interpreting the user's needs, intentions and perspectives, evaluating emotional responses, impressions, and ideas about a product. (Zarour and Alharbi, 2017). User experience research can be used to clarify the specific needs and goals of mHealth users, thereby providing patients with an opportune healthcare experience. (Kirkscey, 2020; Biduski et al., 2020). Notwithstanding, evaluating the real effects of user experience requires long periods, over extended use (Karapanos et al., 2010; Kajiwara and Jin, 2012; Minge and Thüring, 2018). Long-term approaches are also imperative to evaluate treatment adherence, as this can fall off over time. From this perspective, the primary objective of this study was to test the effect of using an mHealth app on patients' adherence to hypertension treatment. The secondary objective was to examine how patients' user experience might have influenced the outcomes.

\section{METHODS}

We conducted a quasi-experimental study (non-randomized, controlled, open-label) and collected participants' data at enrollment and 12 weeks after an mHealth intervention. This time frame was based on the study of Neumann et al. (2015), which justified that at least 3 months were needed to notice long-term effects. This was also considered the minimum period to assess the effects on the user experience (Karapanos et al., 2010; Kajiwara and Jin, 2012; Minge and Thüring, 2018). The local ethics committee of the University of Passo Fundo, under opinion number 3.414.793, approved all procedures involving humans. Written informed consent was obtained from all participants. Registration occurred on the Brazilian Registry of Clinical Trials, code RBR-2rkkgn. This study is a secondary part of a larger multidisciplinary project for health innovation funded by the National Council for Scientific and Technological Development - CNPq and the Ministry of Health of Brazil. The project aims to develop and test a comprehensive electronic health platform to be made available to the Brazilian public health system (De Marchi et al., 2020).

\section{Sample and allocation}

A total of 74 volunteer participants (of whom 49 completed the study) were recruited by phone calls. They were men and women aged 24 to 69 years, diagnosed with arterial hypertension, who were receiving ongoing medical treatment at primary health centers in the city of Passo Fundo, Rio Grande do Sul, Brazil. We attended 2 of these centers to recruit participants on a convenience basis.

The sample size for this study was based on the sample size that will be recruited in the definitive clinical trial of the main project, whose reasoning about estimated effects is detailed in the protocol by De Marchi et al. (2020). Eligibility criteria were: (1) current and ongoing medical monitoring regarding hypertension treatment; (2) minimum score on MMSE cognitive screening test (Brucki et al., 2003); (3) ability to have measurement of blood pressure periodically from an electronic blood pressure cuff or a sphygmomanometer. In addition, participants allocated to the experimental group were required to have 
(1) familiarity with the use of smartphone apps; (2) a smartphone with Android operating system version 5 or higher; (3) Internet access on the smartphone.

The allocation of participants was determined by meeting the final three eligibility criteria. For instance, if the participant met all the criteria but did not have a compatible mobile phone to use the app, then the participant would be allocated to the control group. If the participant had a compatible mobile phone, they would be allocated to the experimental group.

\section{Measurements}

At baseline, we collected basic demographic data from all participants: gender, marital status, age, education level, and monthly household income. Adherence to hypertension treatment was measured at baseline and after follow-up using the Martín-Bayarre-Grau (MBG) questionnaire (Matta et al., 2013; Alfonso et al., 2008). This validated instrument is a cross-cultural adaptation from its original version, which determines the level of adherence according to the operational definition of therapeutic adherence formulated by WHO. The questionnaire includes information about the patient's medication, doctor appointments, treatment, diet, and exercise. It consists of 12 statements answered on a five-point Likert scale (never, almost never, sometimes, almost always and always). The higher score means greater adherence. Participants were classified as "adherent" if they obtained 38 to 48 points, "partial adherent" if they obtained 18 to 37 points and "non-adherent" from 0 to 17 points (Alfonso et al., 2008).

User experience in the experimental group was evaluated using the User Experience Questionnaire (UEQ) (Laugwitz et al., 2008) after follow-up. UEQ is a validated instrument composed of 26 items with a semantic differential rating scale of 7 points. The items are related to the 6 user experience scales of attractiveness, perspicuity, efficiency, dependability, stimulation, and novelty. Attractiveness is a pure valence dimension. Perspicuity, efficiency, and dependability are pragmatic quality aspects (goal-directed), while stimulation and novelty are hedonic quality aspects (not goal-directed) (Zarour and Alharbi, 2017). From responses in 7 semantic differential points, the scores generated by the UEQ range from -3.0 to 3.0. A result less than -0.8 indicates a negative user experience; a result between -0.8 and 0.8 indicates a neutral user experience; a result greater than 0.8 indicates a positive user experience.

\section{Procedure and follow-up}

We instructed participants from both groups to continue their hypertension treatment as usual. For the experimental group, we first installed the mHealth app on the participants' smartphones. Then, we created a user account for each participant and instructed them on how to use the app to record data such as blood pressure and other measurements. During the recruitment process, we helped participants who had difficulty using the app and gave them feedback and more detailed instructions. Health professionals were also made available to assist participants remotely in using the app. Participants could request help from professionals through a text-based chat functionality available on the app.

In the follow-up, the control group had 32 participants who continued their conventional hypertension treatment, without any contact with the app during the study. The experimental group had 36 participants who completed the study using the app for 12 weeks. The mHealth app was developed by Cechetti et al. (2019). It has elements designed to engage patients in self-monitoring of health conditions. It includes the recording of variables (or factors) related to hypertension management, including blood pressure, weight, waist circumference, height, sleep, mood, and engagement in physical activities. Other features include risk assessment based on reference values, recommendations, alerts, and reminders about medication, logbooks of physical activities, and blood pressure measurements. All these elements incorporated in the app are related to a healthy lifestyle that facilitates the treatment of hypertension. Patient data is stored in the cloud for integration with a web dashboard, which allows authorized healthcare professionals to remotely monitor the patient.

\section{Statistical analysis}

Quantitative data were analyzed using the statistical package SPSS 22.0 (IBM Corporation). Descriptive analysis of nominal and ordinal level variables was performed using absolute and relative frequency counts. For continuous variables, we calculated measures of central tendency and dispersion (minimum, maximum, mean, and standard deviation). McNemar's Test was used to test within group differences in treatment adherence. Chi-square test was used to test between group differences. A significance level of 5\% was considered for all analyzes. For the MBG questionnaire, we applied the Mann-Whitney test to compare the score between the groups before and after follow-up. We analyzed the UEQ's responses 
using its proprietary data analysis tool to obtain scores for hedonic and pragmatic qualities and 6 user experience scales.

\section{RESULTS}

Of the 74 enrolled participants, 49 completed follow-up, 24 in the control group and, 25 in the experimental group. Loss to follow-up was due to participants' loss of interest and inability to provide accurate data for analysis. Enrollment and follow-up took place between August and November 2019. Figure 1 shows the study Consort flowchart and Table 1, the demographic characteristics of participants. The mean and standard deviation of participants' age in the control group was $60.4 \pm 10.4$ years and $57.2 \pm 7.1$ years in the experimental group. No statistically significant differences were observed between the experimental and control groups across any of the baseline demographic variables.

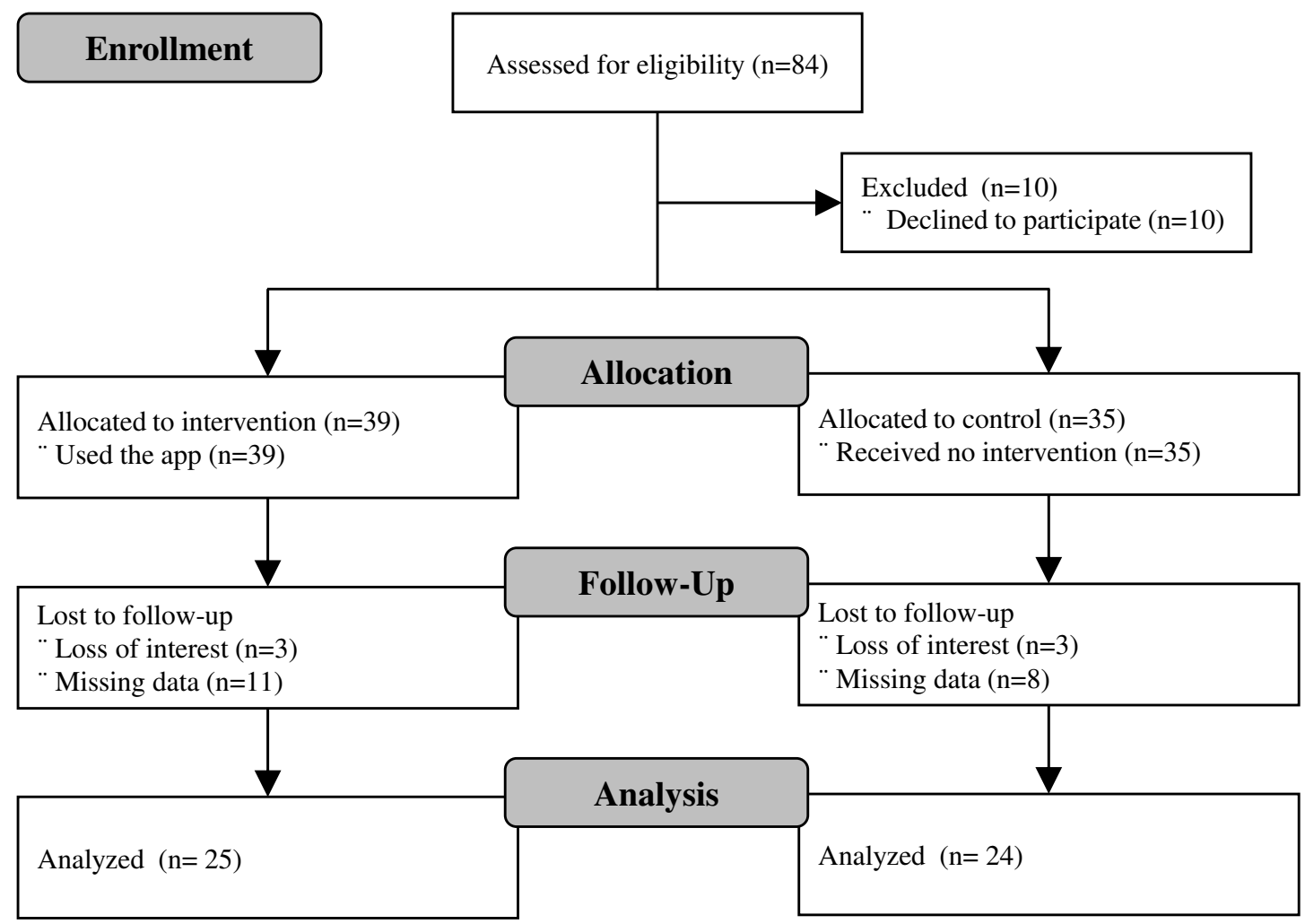

Figure 1. Consort study flowchart.

Figure 2 presents the overall results of the assessment of adherence to hypertension treatment before (baseline) and after follow-up. From the baseline to the after follow-up, the number of adherents in the experimental group increased substantially. Meanwhile, the numbers after follow-up in the control group remained essentially the same. Table 2 presents the tests of differences in adherence to hypertension treatment inter-group and intra-group. Before follow-up, there was no significant difference between groups. After follow-up, the experimental group had a higher prevalence of treatment adherence than the control group. Within groups, treatment adherence was significantly higher at 12 weeks than at baseline for the experimental group but not in the control group.

Table 3 presents the results of the User Experience Questionnaire. The distribution of responses for each item in the questionnaire is illustrated in Figure 3. All results were substantially positive and indicated that the participants in the experimental group had a very positive perception toward the app. Considering these findings, we assumed this satisfactory experience influenced the improvements in adherence of participants from the experimental group. 
Table 1. Baseline demographic characteristics of participants $(\mathrm{N}=49)$.

\begin{tabular}{|c|c|c|c|}
\hline Characteristic & Experimental $(n=25)$ & Control $(n=24)$ & $P$ \\
\hline Gender, n (\%) & & & 0.056 \\
\hline Male & $15(60.0)$ & $8(33.3)$ & \\
\hline Female & $10(40.0)$ & $16(66.7)$ & \\
\hline Age, n (\%) & & & 0.080 \\
\hline 20 to 29 years & $0(0.0)$ & $1(4.2)$ & \\
\hline 40 to 49 years & $4(16.0)$ & $2(8.3)$ & \\
\hline 50 to 59 years & $10(40.0)$ & $3(12.5)$ & \\
\hline 60 to 69 years & $11(44.0)$ & $16(66.7)$ & \\
\hline 70 to 79 years & $0(0.0)$ & $2(8.3)$ & \\
\hline Marital status, n (\%) & & & 0.475 \\
\hline Single & $4(16.0)$ & $3(12.5)$ & \\
\hline Married / stable relationship & $16(64.0)$ & $14(58.3)$ & \\
\hline Divorced & $2(8.0)$ & $3(12.5)$ & \\
\hline Widow(er) & $3(12.0)$ & $4(16.7)$ & \\
\hline Years of study, n (\%) & & & 0.238 \\
\hline 0 to 4 & $1(4.0)$ & $4(16.7)$ & \\
\hline 5 to 8 & $9(36.0)$ & $11(45.8)$ & \\
\hline 9 to 11 & $11(44.0)$ & $5(20.8)$ & \\
\hline 12 or more & $4(16.0)$ & $4(16.7)$ & \\
\hline Is retired, $\mathrm{n}(\%)$ & & & 0.232 \\
\hline Yes & $12(48.0)$ & $15(62.5)$ & \\
\hline No & $13(52.0)$ & $9(37.5)$ & \\
\hline Household income, n (\%) & & & 0.103 \\
\hline None & $0(0.0)$ & $4(16.7)$ & \\
\hline Up to 1 minimum wage & $7(28.0)$ & $5(20.8)$ & \\
\hline 1 to 3 minimum wages & $17(68.0)$ & $12(50.0)$ & \\
\hline 3 to 5 minimum wages & $1(4.0)$ & $3(12.5)$ & \\
\hline
\end{tabular}

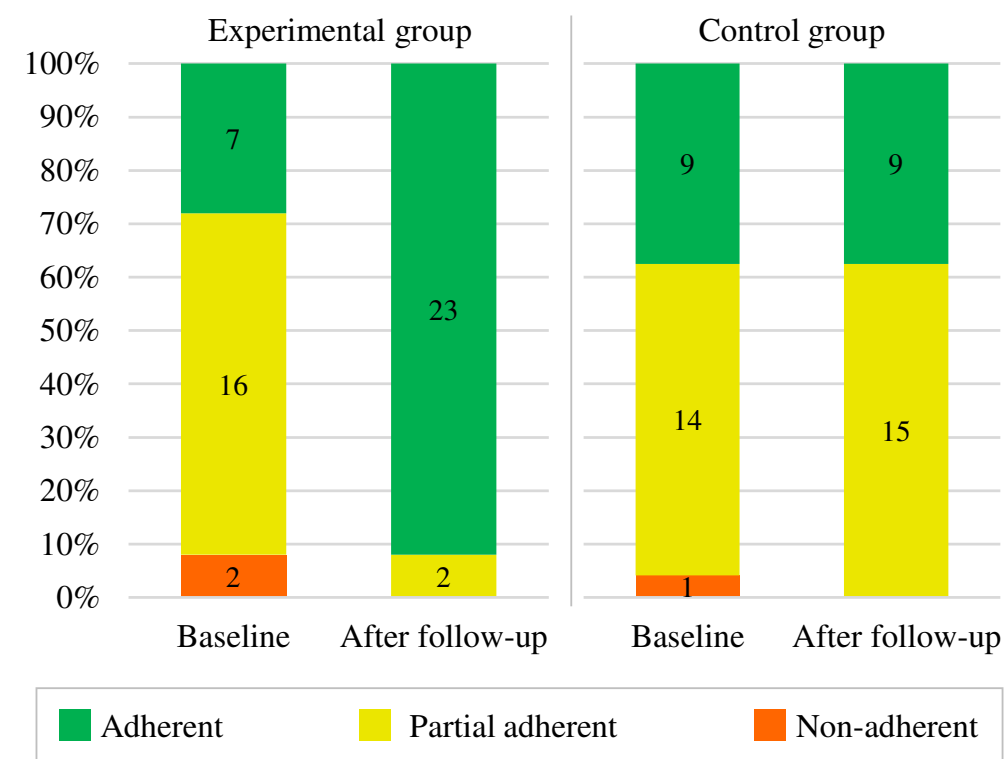

Figure 2. Assessment of adherence to hypertension treatment according to the Martín-Bayarre-Grau questionnaire (N=49). 
Table 2. Comparison of the change in adherence to hypertension treatment inter-groups and intra-groups.

\begin{tabular}{|c|c|c|c|c|c|}
\hline \multirow{2}{*}{ Group } & \multicolumn{2}{|c|}{ Baseline $\left(P=0.343^{*}\right)$} & \multicolumn{2}{|c|}{ After follow-up $\left(P<0.001^{*}\right)$} & \multirow{2}{*}{$P$} \\
\hline & Non-adherent or partial & Adherent & Non-adherent or partial & Adherent & \\
\hline Experimental, n (\%) & $18(72.0)$ & $7(28.0)$ & $2(8.0)$ & $23(82.0)$ & $<0.001 \dagger$ \\
\hline Control, n (\%) & $15(62.5)$ & $9(37.5)$ & $15(62.5)$ & $9(37.5)$ & $\geq 0.999 \dagger$ \\
\hline
\end{tabular}

* Comparison of changes in adherence to hypertension treatment inter-groups using Chi-square Test.

$\dagger$ Comparison of changes in adherence to hypertension treatment intra-groups (baseline versus after follow-up) using McNemar's Test of paired samples.

Table 3. User experience of participants from experimental group $(\mathbf{n}=25)$.

\begin{tabular}{|l|c|c|c|c|}
\hline Category & Mean* & SD & Variance & 95\% CI \\
\hline Pragmatic aspects & 2.60 & 0.06 & 0.42 & 0.20 \\
\hline Hedonic aspects & 2.32 & 0.47 & 0.43 & 0.21 \\
\hline Attractiveness & 2.72 & 0.38 & 0.41 & 0.15 \\
\hline Perspicuity & 2.53 & 0.59 & 0.33 & 0.23 \\
\hline Efficiency & 2.64 & 0.50 & 0.49 & 0.20 \\
\hline Dependability & 2.63 & 0.47 & 0.43 & 0.18 \\
\hline Stimulation & 2.65 & 0.47 & 0.25 & 0.19 \\
\hline Novelty & 1.99 & 0.64 & 0.60 & 0.25 \\
\hline
\end{tabular}

* Results range from -3 to 3 . A value greater than 0.8 indicates a positive and satisfactory user experience.

\section{DISCUSSION}

The control of hypertension is often complex, as it encompasses a variety of factors, ranging from individual aspects of access, difficulties in seeking health services, acquiring medications, following medical prescription, and adaptations to improve lifestyle changes (Macinko et al., 2018; Ferretto et al., 2020). As in this study, others show that supporting mHealth apps has the potential to increase adherence to treatment of patients with hypertension (Santo and Redfern, 2019; Parati et al., 2017).

Health apps can help patients self-manage their health conditions, improve self-assessment, treatment, and control of high blood pressure, including features to collect treatment monitoring data ( $\mathrm{Lu}$ et al., 2019; Liang et al., 2018). Several studies state that participants who used technological resources as an intervention obtained better results when compared to the control group (Debon et al., 2020; Morawski et al., 2018; Andre et al., 2019; Márquez Contreras et al., 2019), similar to our results. Furthermore, apps facilitate communication between patients and healthcare professionals and contribute to patient education (Santo and Redfern, 2019; Debon et al., 2019).

In our study, participants who used the app more actively were between 50 and 69 years old. Hypertension is one of the most prevalent chronic conditions associated with age (Desjardins-Crépeau and Bherer, 2016). Older adults face many health challenges as they age and generally require a relatively large volume of health services (Institute of Medicine of The National Academies, 2008). Conversely, Daniel and Veiga (2013) observed that increasing age was associated with a higher probability of adherence to the recommended treatment. Likewise, Jardim et al. (2017) found better awareness and control in elderly patients. In this sense, the age of participants in this study may have positively influenced adherence.

Akoko et al. (2017) found that factors related to the patient and the health service providers (e.g., regular clinic attendance and condition explanation) showed associations with adherence. Similarly, Duan et al. (2020) affirm the support and guidance of health professionals are reasons for high adherence rates. In our study, we assume that the high adherence to the treatment in the experimental group was also due to the health professionals, who were remotely available to give feedback, assist patients on how to use the app's features, and clarify doubts and concerns that users had about their treatment when necessary. Consequently, these users were more adherent to the treatment, since they received the desired care and felt they were well informed about their condition, as mentioned by Jankowska-Polańska et al. (2016). This type of resource is also fundamental to pave the adoption of telemedicine and remote monitoring technologies, which are playing an increasingly important role for health services amidst the recent 


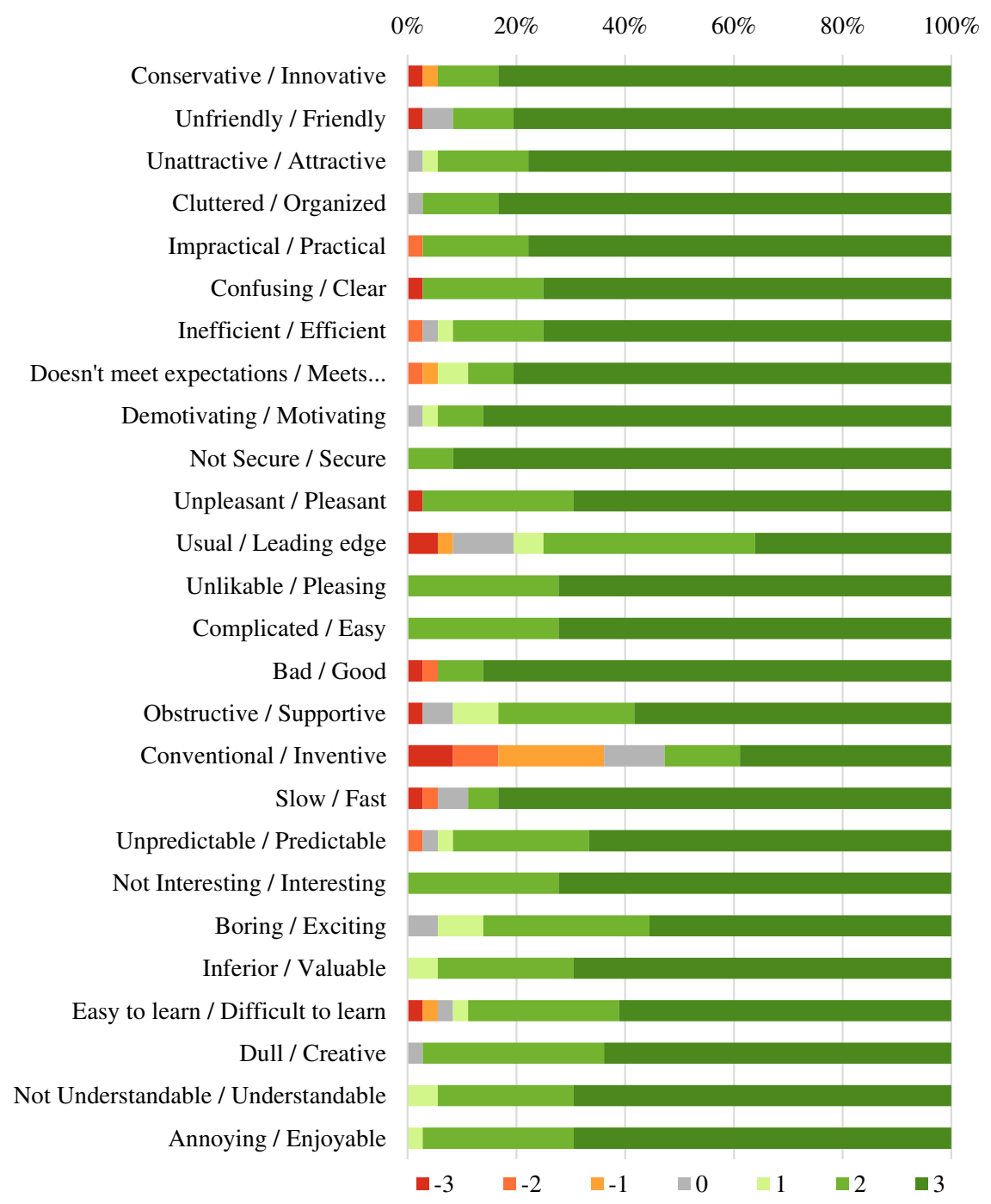

Figure 3. Distribution of answers per item to the User Experience Questionnaire assessing the app usage in the experimental group.

pandemic crisis (Wosik et al., 2020; Smith et al., 2020). Further research is needed to investigate how health professionals and patients can integrate technological advances into daily practice, ensuring the most beneficial and appropriate aspects of technology are effectively used in the health system (Rowland et al., 2020).

Initially, users expressed concern about access, lack of trust, and reduced ability to deal with technology (Albrecht et al., 2017). However, over time, most users realized that through the support provided by the app they could solve problems, reduce insecurities, and improve their self-monitoring, thus making the time spent with the app pleasant and enjoyable, partly due to the intrinsic rewards provided by the gamification system included in the app (Cechetti et al., 2019). These results show that game elements complement the user experience, improving engagement, motivating patients, caregivers, and family members in the quest to acquire more knowledge and use technology to improve health condition (Da Silva Júnior et al., 2021). Hence, as long as the quality of health services can meet the expectations of patients, they will continue to use the services (Guo et al., 2020).

The results of the UEQ questionnaire summarized participants' impressions regarding the influence of experience on the use of the health app. The UEQ categories that obtained the highest means were attractiveness, efficiency, stimulation, and the category related to pragmatic aspects. Two characteristics include the aspects that can influence the user experience, the pragmatic quality, related to the execution of 


\section{REFERENCES}

Akoko, B. M., Fon, P. N., Ngu, R. C., and Ngu, K. B. (2017). Knowledge of Hypertension and Compliance with Therapy Among Hypertensive Patients in the Bamenda Health District of Cameroon: A Crosssectional Study. Cardiology and Therapy, 6(1):53-67.

Albrecht, U.-V., Afshar, K., Illiger, K., Becker, S., Hartz, T., Breil, B., Wichelhaus, D., and von Jan, U. (2017). Expectancy, usage and acceptance by general practitioners and patients: exploratory results from a study in the German outpatient sector. DIGITAL HEALTH, 3:205520761769513.

Alessa, T., Hawley, M. S., Hock, E. S., and de Witte, L. (2019). Smartphone apps to support selfmanagement of hypertension: Review and content analysis. JMIR mHealth and uHealth, 7(5):e13645.

Alfonso, L. M., Vea, H. D. B., and Ábalo, J. A. G. (2008). Validación del cuestionario MBG (MartínBayarre-Grau) para evaluar la adherencia terapéutica en hipertensión arterial. Revista Cubana de Salud Pública, 34(1). 
Anderson, K., Burford, O., and Emmerton, L. (2016). Mobile Health Apps to Facilitate Self-Care: A Qualitative Study of User Experiences. PLOS ONE, 11(5):e0156164.

Andre, N., Wibawanti, R., and Siswanto, B. B. (2019). Mobile Phone-Based Intervention in Hypertension Management. International Journal of Hypertension, 2019:1-7.

Bellei, E. A., Biduski, D., Lisboa, H. R. K., and De Marchi, A. C. B. (2020). Development and assessment of a mobile health application for monitoring the linkage among treatment factors of type 1 diabetes mellitus. Telemedicine and e-Health, 26(2):205-217.

Biduski, D., Bellei, E. A., Rodriguez, J. P. M., Zaina, L. A. M., and De Marchi, A. C. B. (2020). Assessing long-term user experience on a mobile health application through an in-app embedded conversation-based questionnaire. Computers in Human Behavior, 104:106169.

Brucki, S. M., Nitrini, R., Caramelli, P., Bertolucci, P. H., and Okamoto, I. H. (2003). Sugestões para o uso do mini-exame do estado mental no Brasil. Arquivos de Neuro-Psiquiatria, 61(3B):777-781.

Cechetti, N. P., Bellei, E. A., Biduski, D., Rodriguez, J. P. M., Roman, M. K., and De Marchi, A. C. B. (2019). Developing and implementing a gamification method to improve user engagement: A case study with an m-Health application for hypertension monitoring. Telematics and Informatics, 41:126-138.

Chudiak, A., Jankowska-Polańska, B., and Uchmanowicz, I. (2017). Effect of frailty syndrome on treatment compliance in older hypertensive patients. Clinical Interventions in Aging, Volume 12:805814.

Da Silva, T. D. c., Dantas, A. B., Silveira, E. V. d. S., Reis, H. G., Silveira, J. d. P., Caproni, S. M. P., Menezes, B. D., and de Lima, C. C. (2017). Método de adesão ao tratamento de pacientes hipertensos. Archives of Health Investigation, 6(4).

Da Silva Júnior, J. L. A., Biduski, D., Bellei, E. A., Becker, O. H. C., Daroit, L., Pasqualotti, A., Tourinho Filho, H., and De Marchi, A. C. B. (2021). A bowling exergame to improve functional capacity in older adults: Co-design, development, and testing to compare the progress of playing alone versus playing with peers. JMIR Serious Games, 9(1):e23423.

Daniel, A. C. Q. G. and Veiga, E. V. (2013). Fatores que interferem na adesão terapêutica medicamentosa em hipertensos. Einstein (São Paulo), 11(3):331-337.

De Marchi, A. C. B., Alves, A. L. S. A., Gonçalves, C. B. C., Cervi, C. R., Biduski, D., Bellei, E. A., Madalozzo, G. A., Da Cruz, I. B. M., Veiga, J. E., Rodriguez, J. P. M., Ferretto, L. R., Bin, L. C. P., Rebonatto, M. T., Portella, M. R., Roman, M. K., Cechetti, N. P., Rieder, R., Debon, R., and Volpi, S. S. (2020). An Electronic Health Platform for Monitoring Health Conditions of Patients With Hypertension in the Brazilian Public Health System: Protocol for a Nonrandomized Controlled Trial. JMIR Research Protocols, 9(1):e15299.

Debon, R., Bellei, E. A., Biduski, D., Volpi, S. S., Alves, A. L. S., Portella, M. R., and De Marchi, A. C. B. (2020). Effects of using a mobile health application on the health conditions of patients with arterial hypertension: A pilot trial in the context of brazil's family health strategy. Scientific Reports, 10(1).

Debon, R., Coleone, J. D., Bellei, E. A., and De Marchi, A. C. B. (2019). Mobile health applications for chronic diseases: A systematic review of features for lifestyle improvement. Diabetes \& Metabolic Syndrome: Clinical Research \& Reviews, 13(4):2507-2512.

Desjardins-Crépeau, L. and Bherer, L. (2016). Hypertension and age-related cognitive decline. In Hypertension and the Brain as an End-Organ Target, pages 21-38. Springer International Publishing.

Dick, M. E., Schimitt, L. E. A., Gomez, L. R. S., Gonçalves, B. S., and Triska, R. (2016). Experiência antecipada: a influência da imagem da marca na relação dos usuários com aplicativo móvel Spotify. Design e Tecnologia, 6(11):79.

Dou, K., Yu, P., Deng, N., Liu, F., Guan, Y., Li, Z., Ji, Y., Du, N., Lu, X., and Duan, H. (2017). Patients' Acceptance of Smartphone Health Technology for Chronic Disease Management: A Theoretical Model and Empirical Test. JMIR mHealth and uHealth, 5(12):e177.

Duan, H., Wang, Z., Ji, Y., Ma, L., Liu, F., Chi, M., Deng, N., and An, J. (2020). Using GoalDirected Design to Create a Mobile Health App to Improve Patient Compliance With Hypertension Self-Management: Development and Deployment. JMIR mHealth and uHealth, 8(2):e14466.

Egan, B. M. and Zhao, Y. (2012). Different definitions of prevalent hypertension impact: The clinical epidemiology of hypertension and attainment of healthy people goals. The Journal of Clinical Hypertension, 15(3):154-161.

Ferretto, L. R., Bellei, E. A., Biduski, D., Bin, L. C. P., Moro, M. M., Cervi, C. R., and De Marchi, A. C. B. (2020). A physical activity recommender system for patients with arterial hypertension. IEEE 
Access, 8:61656-61664.

Galligioni, E., Piras, E. M., Galvagni, M., Eccher, C., Caramatti, S., Zanolli, D., Santi, J., Berloffa, F., Dianti, M., Maines, F., Sannicolò, M., Sandri, M., Bragantini, L., Ferro, A., and Forti, S. (2015). Integrating mHealth in Oncology: Experience in the Province of Trento. Journal of Medical Internet Research, 17(5):e114.

Gewehr, D. M., Bandeira, V. A. C., Gelatti, G. T., Colet, C. d. F., and de Oliveira, K. R. (2018). Adesão ao tratamento farmacológico da hipertensão arterial na Atenção Primária à Saúde. Saúde em Debate, 42(116):179-190.

Guo, X., Chen, S., Zhang, X., Ju, X., and Wang, X. (2020). Exploring Patients' Intentions for Continuous Usage of mHealth Services: Elaboration-Likelihood Perspective Study. JMIR mHealth and uHealth, 8(4):e17258.

Hui, C. Y., Creamer, E., Pinnock, H., and McKinstry, B. (2019). Apps to support self-management for people with hypertension: Content analysis. JMIR mHealth and uHealth, 7(6):e13257.

Institute of Medicine of The National Academies (2008). Retooling for an Aging America. National Academies Press, Washington, D.C.

Jankowska-Polańska, B., Uchmanowicz, I., Dudek, K., and Mazur, G. (2016). Relationship between patients\&rsquo; knowledge and medication adherence among patients with hypertension. Patient Preference and Adherence, Volume 10:2437-2447.

Jardim, T. V., Reiger, S., Abrahams-Gessel, S., Gomez-Olive, F. X., Wagner, R. G., Wade, A., Bärnighausen, T. W., Salomon, J., Tollman, S., and Gaziano, T. A. (2017). Hypertension management in a population of older adults in rural south africa. Journal of Hypertension, 35(6):1283-1289.

Kajiwara, S. and Jin, Q. (2012). Attachment factor in user experience over a time span. In Proceedings of the 2012 Joint International Conference on Human-Centered Computer Environments - HCCE'12, page 45, New York, New York, USA. ACM Press.

Karapanos, E., Zimmerman, J., Forlizzi, J., and Martens, J.-B. (2010). Measuring the dynamics of remembered experience over time. Interacting with Computers, 22(5):328-335.

Kirkscey, R. (2020). mHealth Apps for Older Adults: A Method for Development and User Experience Design Evaluation. Journal of Technical Writing and Communication, page 004728162090793.

Kitt, J., Fox, R., Tucker, K. L., and McManus, R. J. (2019). New Approaches in Hypertension Management: a Review of Current and Developing Technologies and Their Potential Impact on Hypertension Care. Current Hypertension Reports, 21(6):44.

Laugwitz, B., Held, T., and Schrepp, M. (2008). Construction and Evaluation of a User Experience Questionnaire. In Holzinger, A., editor, HCI and Usability for Education and Work, pages 63-76, Berlin, Heidelberg. Springer Berlin Heidelberg.

Liang, J., He, X., Jia, Y., Zhu, W., and Lei, J. (2018). Chinese Mobile Health APPs for Hypertension Management: A Systematic Evaluation of Usefulness. Journal of Healthcare Engineering, 2018:1-14.

Lu, X., Yang, H., Xia, X., Lu, X., Lin, J., Liu, F., and Gu, D. (2019). Interactive Mobile Health Intervention and Blood Pressure Management in Adults. Hypertension, 74(3):697-704.

Macinko, J., Leventhal, D. G. P., and Lima-Costa, M. F. (2018). Primary Care and the Hypertension Care Continuum in Brazil. Journal of Ambulatory Care Management, 41(1):34-46.

Mancia, G., Fagard, R., Narkiewicz, K., Redón, J., Zanchetti, A., Böhm, M., Christiaens, T., Cifkova, R., Backer, G. D., Dominiczak, A., Galderisi, M., Grobbee, D. E., Jaarsma, T., Kirchhof, P., Kjeldsen, S. E., Laurent, S., Manolis, A. J., Nilsson, P. M., Ruilope, L. M., Schmieder, R. E., Sirnes, P. A., Sleight, P., Viigimaa, M., Waeber, B., and Zannad, F. (2013). 2013 ESH/ESC guidelines for the management of arterial hypertension. Journal of Hypertension, 31(7):1281-1357.

Márquez Contreras, E., Márquez Rivero, S., Rodríguez García, E., López-García-Ramos, L., Carlos Pastoriza Vilas, J., Baldonedo Suárez, A., Gracia Diez, C., Gil Guillén, V., and Martell Claros, N. (2019). Specific hypertension smartphone application to improve medication adherence in hypertension: a cluster-randomized trial. Current Medical Research and Opinion, 35(1):167-173.

Matta, S. R., Luiza, V. L., and Azeredo, T. B. (2013). Adaptacao brasileira de questionario para avaliar adesao terapeutica em hipertensao arterial. Revista de Saúde Pública, 47(2):292-300.

McLean, G., Band, R., Saunderson, K., Hanlon, P., Murray, E., Little, P., McManus, R. J., Yardley, L., and Mair, F. S. (2016). Digital interventions to promote self-management in adults with hypertension systematic review and meta-analysis. Journal of Hypertension, 34(4):600-612.

Miller, T. A. (2016). Health literacy and adherence to medical treatment in chronic and acute illness: A 
meta-analysis. Patient Education and Counseling, 99(7):1079-1086.

Minge, M. and Thüring, M. (2018). Hedonic and pragmatic halo effects at early stages of User Experience. International Journal of Human-Computer Studies, 109:13-25.

Morawski, K., Ghazinouri, R., Krumme, A., Lauffenburger, J. C., Lu, Z., Durfee, E., Oley, L., Lee, J., Mohta, N., Haff, N., Juusola, J. L., and Choudhry, N. K. (2018). Association of a Smartphone Application With Medication Adherence and Blood Pressure Control. JAMA Internal Medicine, 178(6):802.

Neumann, C. L., Menne, J., Schettler, V., Hagenah, G. C., Brockes, C., Haller, H., and Schulz, E. G. (2015). Long-Term Effects of 3-Month Telemetric Blood Pressure Intervention in Patients with Inadequately Treated Arterial Hypertension. Telemedicine and e-Health, 21(3):145-150.

Ni, Z., Dardas, L., Wu, B., and Shaw, R. (2019). Cardioprotective medication adherence among patients with coronary heart disease in china: a systematic review. Heart Asia, 11(2):e011173.

Ni, Z., Liu, C., Wu, B., Yang, Q., Douglas, C., and Shaw, R. J. (2018). An mHealth intervention to improve medication adherence among patients with coronary heart disease in china: Development of an intervention. International Journal of Nursing Sciences, 5(4):322-330.

Paglialonga, A., Lugo, A., and Santoro, E. (2018). An overview on the emerging area of identification, characterization, and assessment of health apps. Journal of Biomedical Informatics, 83:97-102.

Parati, G., Torlasco, C., Omboni, S., and Pellegrini, D. (2017). Smartphone Applications for Hypertension Management: a Potential Game-Changer That Needs More Control. Current Hypertension Reports, 19(6):48.

Roman, M. K., Bellei, E. A., Biduski, D., Pasqualotti, A., De Araujo, C. D. S. R., and De Marchi, A. C. B. (2020). "Hey assistant, how can I become a donor?" the case of a conversational agent designed to engage people in blood donation. Journal of Biomedical Informatics, 107:103461.

Rowland, S. P., Fitzgerald, J. E., Holme, T., Powell, J., and McGregor, A. (2020). What is the clinical value of mHealth for patients? npj Digital Medicine, 3(1):4.

Sabaté, E. (2003). Adherence to long-term therapies : evidence for action. World Health Organization, Geneva.

Santo, K. and Redfern, J. (2019). The Potential of mHealth Applications in Improving Resistant Hypertension Self-Assessment, Treatment and Control. Current Hypertension Reports, 21(10):81.

Smith, W. R., Atala, A. J., Terlecki, R. P., Kelly, E. E., and Matthews, C. A. (2020). Implementation Guide for Rapid Integration of an Outpatient Telemedicine Program during the COVID-19 Pandemic. Journal of the American College of Surgeons.

Toro-Ramos, T., Lee, D.-H., Kim, Y., Michaelides, A., Oh, T. J., Kim, K. M., Jang, H. C., and Lim, S. (2017). Effectiveness of a Smartphone Application for the Management of Metabolic Syndrome Components Focusing on Weight Loss: A Preliminary Study. Metabolic Syndrome and Related Disorders, 15(9):465-473.

Uchmanowicz, B., Chudiak, A., Uchmanowicz, I., Rosińczuk, J., and Froelicher, E. S. (2018). Factors influencing adherence to treatment in older adults with hypertension. Clinical Interventions in Aging, 13:2425-2441.

Whelton, P. K. (2015). The Elusiveness of Population-Wide High Blood Pressure Control. Annual Review of Public Health, 36(1):109-130.

Wosik, J., Fudim, M., Cameron, B., Gellad, Z. F., Cho, A., Phinney, D., Curtis, S., Roman, M., Poon, E. G., Ferranti, J., Katz, J. N., and Tcheng, J. (2020). Telehealth transformation: COVID-19 and the rise of virtual care. Journal of the American Medical Informatics Association.

Xiong, S., Berkhouse, H., Schooler, M., Pu, W., Sun, A., Gong, E., and Yan, L. L. (2018). Effectiveness of mHealth Interventions in Improving Medication Adherence Among People with Hypertension: a Systematic Review. Current Hypertension Reports, 20(10):86.

Zarour, M. and Alharbi, M. (2017). User experience framework that combines aspects, dimensions, and measurement methods. Cogent Engineering, 4(1). 